\title{
Critical Care Junior Doctors' Profile in a Lower Middle-income Country: A National Cross-sectional Survey
}

\author{
Ambepitiyawaduge Pubudu De Silva',2, D. D. S. Baranage ${ }^{3}$, Anuruddha Padeniya ${ }^{4,5,6}$, Ponsuge Chathurani Sigera $^{1,3}$, Sunil De Alwis ${ }^{7}$, \\ Anuja Unnathie Abayadeera ${ }^{8}$, Palitha G. Mahipala ${ }^{9}$, Kosala Saroj Jayasinghe ${ }^{8}$, Arjen M. Dondorp ${ }^{10}$, Rashan Haniffa ${ }^{1,3,10}$ \\ ${ }^{1}$ National Intensive Care Surveillance, Ministry of Health, Sri Lanka, ${ }^{2}$ Intenisve Care National Audit and Research Centre, London, United Kingdom, ${ }^{3}$ Network for Improving \\ Critical Care Systems and Training, Colombo, ${ }^{4}$ Paediatric Neurology Unit, Lady Ridgeway Hospital, Colombo, ${ }^{5}$ Faculty of Medicine, University of Rajarata, Anuradhapura, \\ ${ }^{6}$ Sri Lanka Government Medical Officers Association, Colombo, ${ }^{7}$ Education, Training and Research Unit, Ministry of Health, ${ }^{8}$ Faculty of Medicine, University of Colombo, \\ Colombo, ${ }^{9}$ Direcotr General's Office, Ministry of Health, Colombo, Sri Lanka, ${ }^{10}$ Mahidol Oxford Tropical Medicine Research Unit. Bangkok, Thailand
}

\section{Abstract}

Background and Aims: Retention of junior doctors in specialties such as critical care is difficult, especially in resource-limited settings. This study describes the profile of junior doctors in adult state intensive care units in Sri Lanka, a lower middle-income country. Materials and Methods: This was a national cross-sectional survey using an anonymous self-administered electronic questionnaire. Results: Five hundred and thirty-nine doctors in 93 Intensive Care Units (ICUs) were contacted, generating 207 responses. Just under half of the respondents $(93,47 \%)$ work exclusively in ICUs. Most junior doctors $(150,75.8 \%)$ had no previous exposure to anesthesia and $134(67.7 \%)$ had no previous ICU experience while 116 (60.7\%) ICU doctors wished to specialize in critical care. However, only a few (12, 6.3\%) doctors had completed a critical care diploma course. There was a statistically significant difference $(P<0.05)$ between the self-assessed confidence of anesthetic background junior doctors and non-anesthetists. The overall median competency for doctors improves with the length of ICU experience and is statistically significant $(P<0.05)$. ICU postings were less happy and more stressful compared to the last non-ICU posting $(P<0.05$ for both). The vast majority, i.e., $173(88.2 \%)$ of doctors felt the care provided for patients in their ICUs was good, very good, or excellent while 71 doctors (36.2\%) would be happy to recommend the ICU where they work to a relative with the highest possible score of 10. Conclusion: Measures to improve training opportunities for these doctors and strategies to improve their retention in ICUs need to be addressed.

Keywords: Critical care, junior doctors, lower middle-income country, resource-limited setting, training

\section{INTRODUCTION}

Critical care medicine is an established, especially in high-income countries (HICs), and an increasingly independent specialty. Universally, junior doctors and Intensive Care Unit (ICU) nurses are at the forefront of providing ICU care. The distribution of doctors, their training, and skills play a role in determining ICU outcomes. ${ }^{[1]}$ In HIC countries such as Australia and the United Kingdom, critical care specialists are trained through a comprehensive program similar to any other clinical discipline. Sri Lanka, in contrast to many lower middle-income countries (LMICs) where such programs are nonexistent, has a fledgling program for specialist adult critical care training. ${ }^{[2]}$

Doctors working in ICUs require specialist skills and invariably work in a stressful environment. For example, junior doctors

\begin{tabular}{|l|l|}
\hline \multicolumn{2}{|c|}{ Access this article online } \\
\hline Quick Response Code: & Website: \\
\hline & www.ijccm.org \\
\cline { 2 - 2 } & \\
\hline
\end{tabular}

face difficulties in managing airway emergencies especially if they have not had previous exposure to anesthesia/ICU. ${ }^{[3]}$ Doctors when allocated to ICUs experience stress, which is likely to be greater in non-HIC countries, and is compounded by staff shortages, high turnover, and increased caseloads. ${ }^{[4,5]}$ Perhaps, consequently, retention of junior doctors (and nurses) in specialties such as critical care is difficult, especially in resource-limited settings. ${ }^{[6,7]}$ Frontline staffs in LMIC ICUs, in addition, face difficulties related to resource limitations

Address for correspondence: Dr. Rashan Haniffa, National Intensive Care Surveillance, Quality Secretariat Building, Castle Street Hospital for Women, Colombo, Sri Lanka. E-mail: rashan@nicslk.com

This is an open access article distributed under the terms of the Creative Commons Attribution-NonCommercial-ShareAlike 3.0 License, which allows others to remix, tweak, and build upon the work non-commercially, as long as the author is credited and the new creations are licensed under the identical terms.

For reprints contact: reprints@medknow.com

How to cite this article: De Silva AP, Baranage D, Padeniya A, Sigera PC, De Alwis S, Abayadeera AU, et al. Critical care junior doctors' profile in a lower middle-income country: A national cross-sectional survey. Indian J Crit Care Med 2017;21:733-9. 
and organizational aspects of critical care. For instance, in low-income countries of the African continent, ICU patients are cared for by the doctors in base specialties. ${ }^{[8]}$ Junior doctors will thus be very aware of the strengths and limitations of services they provide and are likely to be central to improvement strategies. There are however limited studies from LMIC settings focusing on ICU staff. ${ }^{[6,9]}$

In Sri Lanka, state critical care is spread over 500 beds in approximately 100 ICUs with an average doctor: ICU bed ratio of 1.16:1. ${ }^{[10]}$ All junior doctors, not training to be consultants (specialists) and not in a formal postgraduate training program, are allocated 4-year rotational postings by a centralized transfer system which is administered by the Ministry of Health (MOH). This system has been designed to ensure that less popular settings and specialties are adequately staffed by means of an easy to administer system. The allocations depend on vacancies, seniority, doctors' preference, and previous hospital of employment. Qualifications, specialty courses, special skills, or relevant training are not priority considerations. In parallel, doctors enrolled in formal postgraduate training to be consultants (specialists) are allocated posts through an alternative allocation system, tailored to their training needs.

The aim of this national cross-sectional survey was to determine the profiles and training needs of junior doctors working in state ICUs in Sri Lanka to inform strategies to improve retention, training and service delivery.

\section{Materials and Methods}

This was a cross-sectional survey aimed at all state sector adult ICU doctors. Private sector ICUs in Sri Lanka were excluded as they are predominantly staffed by junior doctors from state hospitals doing extra shifts. Pediatric and neonatal ICUs were also excluded. Ethical review was obtained from the ethical review board of the Faculty of Medicine, University of Colombo, Sri Lanka (EC-14-009).

All state sector adult ICUs were contacted to ascertain contact details of junior doctors. The ICUs which declined to provide contact details of doctors following a second attempt by a senior investigator were not pursued any further. The doctors, whose contact details were thus obtained, were contacted by telephone by an investigator and invited to participate in the survey.

A self-administered anonymous electronic questionnaire was utilized for the study. The survey instrument (developed by DB, CS, APDS, and RH) underwent pre- and pilot-testing by AA, SDS, and KSJ as well as selected junior doctors with regard to its flow, salience, acceptability, and administrative ease. Inter-rater reliability was also assessed. Based on the results of the pilot-testing, the questionnaire was modified. Finally, clinical sensitivity testing as well as testing for internal validity was conducted. Free text responses were minimized by the using dropdown menus and radio buttons (for Likert scales) to facilitate user entry and statistical analysis. The questionnaire covered the following: ICU training needs and career aspirations; ICU competencies and stress; and junior doctors' views on how LMIC ICUs can improve services. Questions deemed central to the study were made mandatory to minimize incomplete responses. The survey tool was made available on a dedicated website, and automated field validation was used to minimize erroneous entries. Frequently asked questions were made available on the website alongside contact details for any clarifications. The survey tool was only available in English.

Approval for the study was obtained from the $\mathrm{MOH}$ (Directorate for Education, Training, and Research) and supported by the Government Medical Officers Association. The professional organizations concerned with critical care in the country were informed about the study and were requested to facilitate the survey.

The junior doctors whose contact details were obtained from the ICUs were contacted over the telephone. Any doctor who declined consent was not contacted again. The survey form was then emailed to these doctors followed by a short message service (SMS) alert. Two weeks after the link was shared, reminders were sent by E-mail and SMS. The doctors were requested to convey contact details of other eligible colleagues directly to the investigators, to ensure that as many as possible were contacted. The survey was also offered over the telephone as an interviewer-administered instrument or by post. At the end of the study period, questionnaire accessibility through the study homepage was blocked and raw data were manually checked independently by two authors for plausibility and quality control. Duplicates were removed and exclusion criteria (doctors predominantly working in pediatric or neonatal ICUs) enforced.

All Likert scales ranged from 0 to 10 and were mapped into five groups after the survey for analysis; $0,1-3,4-6,7-9$, and 10. Overall competency was a mean score calculated from 8 ICU skills scored from 0 to 10 . Data were analyzed using STATA 13 and $\mathrm{R}$ version 3.3.1 (StataCorp). Summary of results was presented in tables by counts and percentages. Nonparametric tests were used for Likert scale responses. Wilcoxon signed-rank test was used to compare two paired groups while MannWhitney U-test for unpaired two groups with Likert scale. Kruskal-Wallis test was used to compare if there were more than two independent groups with Likert scale. All tests were two-sided and level of significance was taken as 0.05 .

\section{REsULTS}

Ninety-three adult ICUs were contacted with 5 ICUs declining to participate. A total of 539 doctors from the agreeable ICUs were contacted [Figure 1]. The total number of responses received, after removing duplicates, was 207. Nine were discarded as they were doctors primarily employed at pediatric or neonatal ICUs. All doctors preferred the online questionnaire, and administration through the telephone/post was not necessary. 
De Silva, et al.: Critical care junior doctors' profile

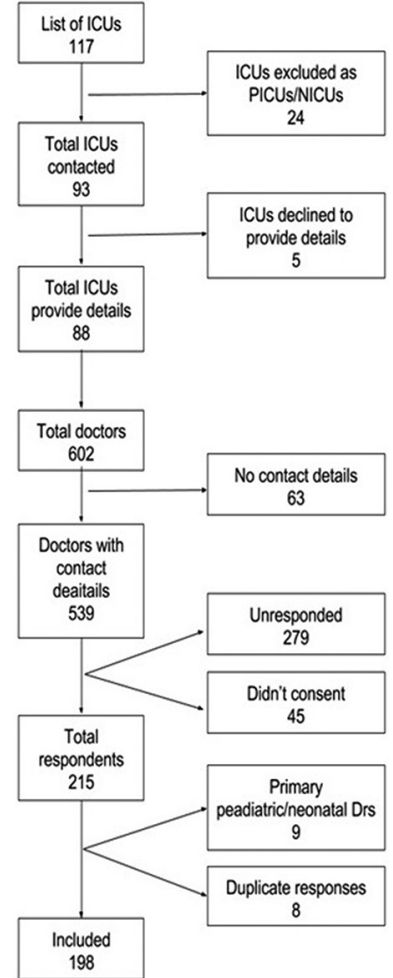

Figure 1: Summarizes the study population

Table 1 summarizes the profile of the respondents. The mean age of the doctors was 35 years (standard deviation $=5$ ) with $86(43.4 \%)$ doctors in the 31-35-year category. For over two-thirds of the doctors $(134,67.7 \%)$, this was their first ICU job. A total of 155 (78.28\%) doctors had a formal induction (orientation) at the commencement of their ICU posting.

Overall, $68(34.3 \%)$ respondents identified themselves as anesthetic junior doctors and 66 doctors (33.3\%) categorized themselves as critical care junior doctors. The remaining doctors ascribed themselves to other specialties or none. Just under half of the respondents $(93,47 \%)$ work exclusively in ICUs with no allocated duties outside these units. Overall, 57 doctors $(28.8 \%)$ work in more than one ICU. It is notable that 150 doctors $(75.8 \%)$ had no previous exposure to anesthesia before this ICU appointment and only 4 respondents $(2.1 \%)$ had any ICU training overseas. Twelve (6.3\%) doctors had already completed a critical care diploma course conducted by the national Postgraduate Institute of Medicine. One hundred and sixteen (60.7\%) ICU doctors expressed a wish to specialize in critical care as a postgraduate specialty. In addition, 99 doctors $(50.5 \%)$ were able to recommend critical care, with the highest possible recommendation (10 on a Likert scale of 0-10), as a specialty in Sri Lanka to a colleague. Only 2 doctors marked "zero" for this specialty recommendation. Similarly, in response to how likely they were to choose this ICU posting again, 72 (36.92\%) doctors indicated complete certainty with a score of 10 (on a Likert scale of 0-10) with 130 (66.67\%) doctors scoring between 7 and 10 on a $0-10$ Likert scale.

\begin{tabular}{lc}
\hline \multicolumn{2}{l}{ Table 1: Profile of junior Intensive Care Unit doctors } \\
\hline Characteristic & $\boldsymbol{n}(\%)$ \\
\hline Age & \\
$26-30$ & $35(17.68)$ \\
$31-35$ & $86(43.43)$ \\
$36-40$ & $41(20.71)$ \\
$41-45$ & $32(16.16)$ \\
$46-50$ & $2(1.01)$ \\
$>50$ & $2(1.01)$ \\
Gender & \\
Male & $104(53.33)$ \\
Female & $91(46.67)$ \\
ICU & \\
General & $89(44.95)$ \\
Medical & $35(17.68)$ \\
Surgical & $25(12.63)$ \\
Special & $49(24.7)$ \\
Duties & \\
Only ICU & $93(46.97)$ \\
More in ICU and less in theater & $27(13.64)$ \\
More in theaters and less in ICU & $52(26.26)$ \\
More in ICU and less in wards & $6(3.03)$ \\
More in wards and less in ICU & $14(7.07)$ \\
More in ICU and less in OPD and other & $4(2.02)$ \\
More in OPD and other and less in ICU & $2(1.01)$ \\
Proportion of time in ICU shifts (\%) & \\
$<20$ & $13(6.88)$ \\
$21-40$ & $40(21.16)$ \\
$41-60$ & $25(13.23)$ \\
$61-80$ & $10(5.29)$ \\
$81-99$ & $6(3.17)$ \\
100 & $95(50.26)$ \\
\hline OPD: Outpatient department; ICU: Intensive Care Unit \\
(1)
\end{tabular}

A majority $(133,67.2 \%)$ of doctors also felt well supervised and $102(51.52 \%)$ respondents had a named educational supervisor for their current ICU posting.

Table 2 further summarizes the training needs related to relevant short courses. Figure 2 illustrates junior doctors' self-assessed competence in 8 common ICU skills. The median self-assessed competency for junior doctors who have been in a previous ICU post was 8.9 (interquartile range [IQR] 1.6) when compared with the median value of 8 (IQR 2.25) for those who have not held a previous ICU post. This difference was statistically significant $(P<0.05)$. The overall median competency progressively improves with the length of ICU experience; $<12$ months experience median of 6.88 and IQR $2.75 ; 1-4$ years experience median 8.69 and IQR $1.62 ;>4$ years median of 9 and IQR 1.25. These differences are also statistically significant $(P<0.05)$. Overall, there was also a statistically significant difference $(P<0.05)$ between the median self-assessed confidence of anesthetic junior doctors (median 8.9, IQR 1.75) and non-anesthetic junior doctors (median 8.1, IQR 2.38). Figure 3 illustrates the distribution of ICU doctors' self-perceived happiness and stress. There was a statistically significant difference in 


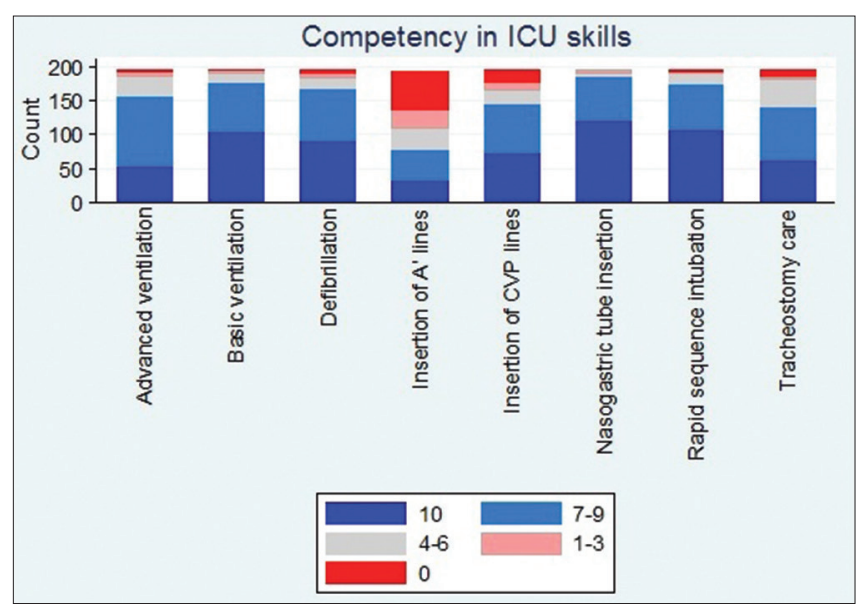

Figure 2: Self-assessed competency in 8 common Intensive Care Unit skills

\begin{tabular}{lc}
\hline $\begin{array}{l}\text { Table 2: Intensive Care Unit junior doctors views on short } \\
\text { Courses }\end{array}$ & $\boldsymbol{n}(\%)$ \\
\hline Relevant courses & $112(57.1)$ \\
\hline ALS & $71(36.2)$ \\
Willing to do & $13(6.6)$ \\
Already done & \\
Not interested & $183(92.9)$ \\
Practical medical emergencies course & $4(2.0)$ \\
Willing to do & $10(5.1)$ \\
Already done & \\
Not interested & $180(91.4)$ \\
Simulation training for ICU/emergencies & $3(1.5)$ \\
Willing to do & $14(7.1)$ \\
Already done & \\
Not interested & $169(85.8)$ \\
BASICS & $12(6.1)$ \\
Willing to do & $16(8.1)$ \\
Already done & \\
Not interested &
\end{tabular}

stress and happiness levels when ICU postings and the last non-ICU posting $(P<0.05)$ were compared, with the ICU posting being perceived to be more stressful and feeling less happy.

The vast majority, i.e., 173 (88.2\%) of doctors felt the care provided for patients in their ICUs was good, very good, or excellent. Seventy-one doctors (36.2\%) would be happy to recommend ICU where they work to a relative with the highest possible score of 10 (on a 0-10 Likert scale) with 139 doctors (70.9\%) scoring this recommendation between 7 and 10 . The challenges experienced by these ICU junior doctors are shown in Figure 4 and in supplementary information. The barriers faced by their ICUs and strategies for improvements as perceived by the doctors are shown in Figures 5 and 6 and also in supplementary material.

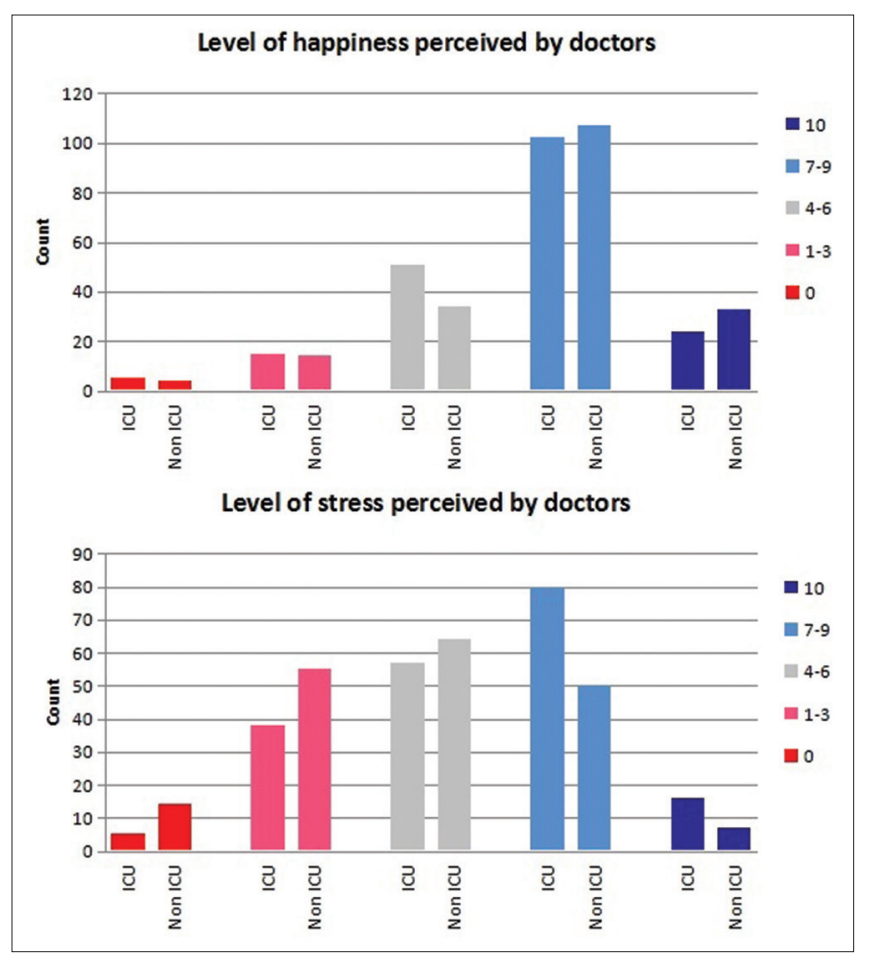

Figure 3: The comparison of level of stress and happiness of doctors working in Intensive Care Units and in their last non-Intensive Care Unit posting

\section{Discussion}

This national survey of adult critical care junior doctors is a first for an LMIC. Most (67.7\%) respondents are in their first ICU posting and are not currently part of a formal critical care training program. However, unlike similar settings, the doctors did not predominantly originate from an anesthetic background. ${ }^{[4,5]}$ These critical care junior doctors are both significantly more stressed and significantly less happy in comparison to their last non-ICU posting, even though this did not deter them from aspiring to critical care as a career for themselves or when recommending to a colleague. In addition, the junior doctors overwhelmingly perceived ICU care provided by their unit as good and had no hesitation in recommending the ICU as part of a "Friends and Family Test". ${ }^{[1]}$

The survey response rate was $40.1 \%$ among those who consented to participate. This figure necessitates caution when interpreting the study findings. The low response rate is in contrast to the $100 \%$ response rate in the national survey of physiotherapists ${ }^{[12]}$ and the survey of ICU services ${ }^{[10]}$ by the same group of investigators. The low response rate is despite measures to improve participation; contacting the doctors through their ICU, reminding those who consented by text messages and E-mail, ensuring and reassuring anonymity, study being conducted by a multidisciplinary group, obtaining ethical review, securing $\mathrm{MOH}$ approval for the study, obtaining the endorsement of the doctors' union, approaching the relevant academic professional colleges and making the survey available in multiple (online and nononline) formats. 


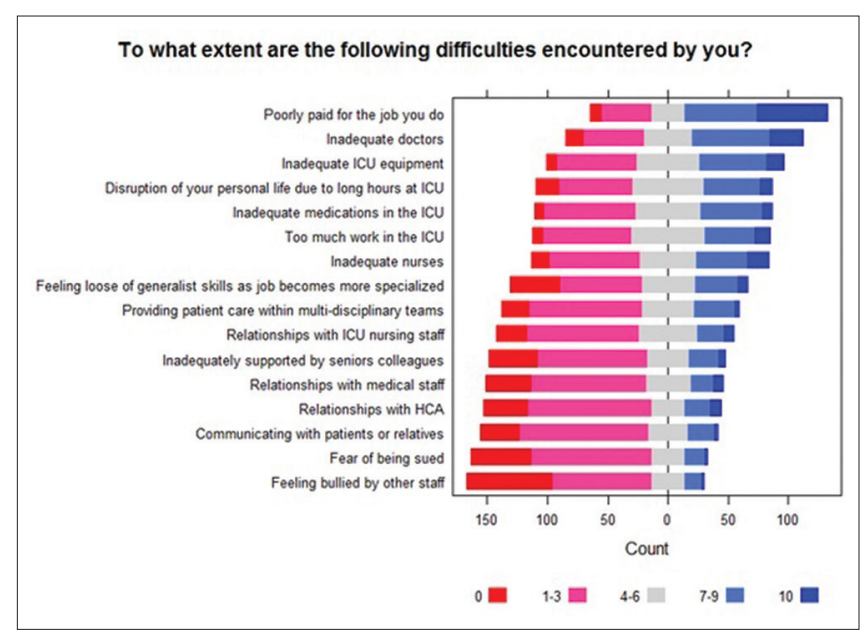

Figure 4: The challenges experienced by Intensive Care Unit junior doctors

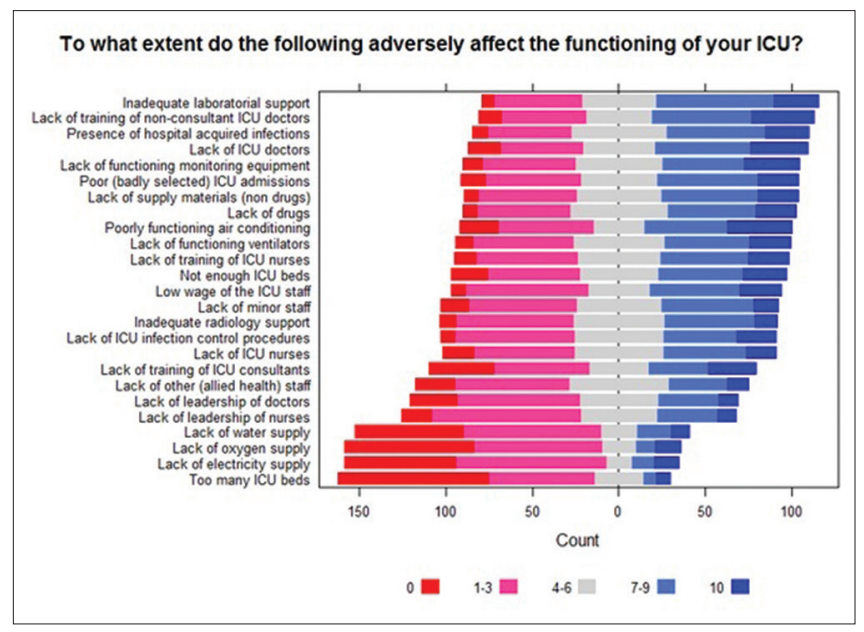

Figure 5: The barriers faced by junior doctors in Intensive Care Unit

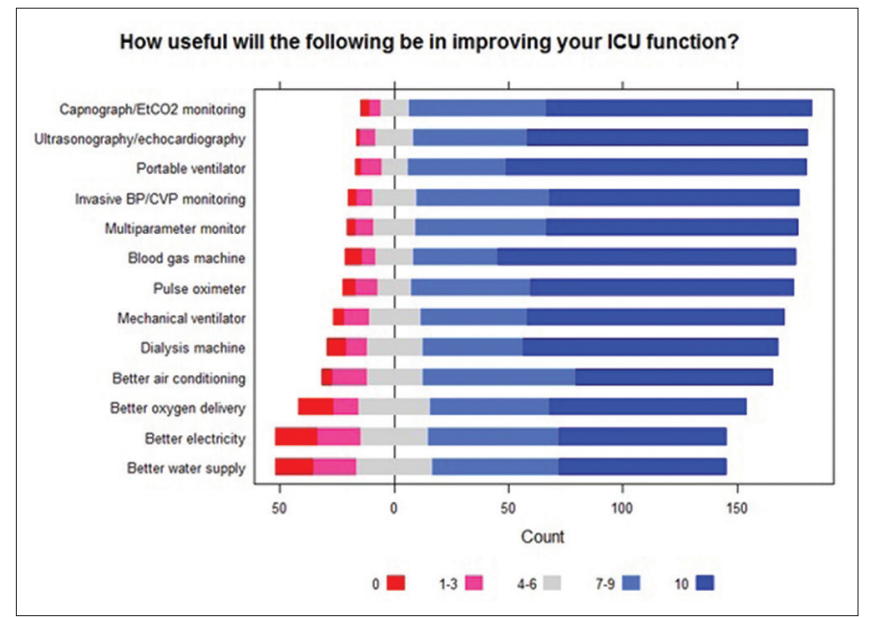

Figure 6: Strategies for improvements in Intensive Care Unit function as perceived by junior doctors

The sensitive nature of the questions, the length of the survey, online (primary) format of the survey, and the unfamiliarity of these doctors toward surveys in this setting may have contributed to a low response rate. These possibilities need further exploration, especially to inform the conduct of future surveys of doctors in this setting, bearing in mind difficulties in ensuring adequate doctors' participation in non-mandatory surveys are not limited to ICUs or LMICs. ${ }^{[13]}$ To enhance participation, the use of more innovative techniques such as social media or very short survey tools or alternative modes such as a telephone interview, which has been previously successful in this setting, merit further consideration.

The staffing and retention of doctors in specialties such as emergency and critical care medicine is a universal problem, and perhaps worse in LMICs. ${ }^{[6,7]}$ The importance of appropriate specialist medical staffing of ICUs has been internationally recognized. The College of Intensive Care Medicine of Australia and New Zealand recommends that only "a registered medical practitioner with an appropriate level of experience" should be exclusively rostered and predominantly present in the ICU at all times. ${ }^{[4]}$ However, especially at night, many hospitals including those of HICs lack resident doctors with adequate competencies to manage ICU airway emergencies. ${ }^{[4,5]}$ In Australia and New Zealand, only $15 \%$ of units had a dedicated resident doctor to manage complex/emergency airway issues at night time. Similar difficulties were observed in limited studies in non-HIC, compounded by severe staffing limitations and increased caseloads. ${ }^{[8]}$

This study confirms previous reports that Sri Lankan adult critical care units are relatively well staffed, with junior doctors' staffing ratios being comparable to countries with better resources. ${ }^{[14-16]}$ However, this survey reveals that more than half of the junior doctors have clinical commitments outside critical care and that most junior doctors currently working in Sri Lankan ICUs had no previous critical care experience. This is due to junior doctors who previously held such ICU posts moving to noncritical care postings or leaving the state sector. The underlying reasons for this worrying pattern need to be explored and remedial measures need to be instituted. The lack of retention is perhaps surprising given that the junior doctors surveyed would choose their current ICU posting, if allowed to revisit their choice, despite the significantly lower levels of self-reported happiness and higher levels of stress, when compared to previous non-ICU postings. However, they were not explicitly asked as to whether they would take up another ICU posting as their next job. This study is unable to delineate the relative contributions of the Sri Lankan doctors' allocation system, overseas migration (known to be a problem in this setting), stress, lifestyle preferences, or other factors. This transitional junior doctor population with a high annual turnover can make service provision very challenging, especially in areas such as critical care, where specialist technical skills are acquired over the years (as evidenced by this study) and where multidisciplinary care plays an increasingly important role. Therefore, in Sri Lanka, skills acquired by critical care junior doctors are not being retained within the specialty, necessitating the retraining of a high proportion of junior 
doctors posted to ICUs every year. In addition, given the junior doctors' allocation system, such challenges are unlikely to be limited to critical care medicine and justify further investigation and implementation of remedial measures with the involvement of the different stakeholders.

Doctors previously employed in an ICU were significantly more competent in ICU technical skills. Their perceived competency in these skills also improved with increasing ICU experience. These findings, corroborated by studies in HIC settings, support the need for retaining expertise within the specialty by minimizing turnover. In parallel, new doctors starting out in critical care will require training to gain the necessary skills without compromising patient safety. These novice doctors will require robust supervision, mentoring, and orientation as they acquire these skills on the ICU to support them and ensure patient safety. It is reassuring to note that more than three-quarters of the doctors had some form of formal orientation at the start of their posting and just over half had a named educational supervisor.

Given that a majority of technical skills are common to critical care and anesthesia, junior doctors from an anesthetic background were significantly more competent in ICU technical skills when compared to those who had no anesthetic experience. This supports the preferential deployment of junior doctors with anesthetic/critical care skills in ICUs. Such allocated junior doctors could also mentor and support their colleagues with no exposure to anesthesia/critical care in a formal but peer-led capacity, until the latter gain the requisite competencies.

A majority of the respondents from this survey expressed a desire to specialize in critical care if given the opportunity. There is recognition that training opportunities in critical care in Sri Lanka need to be widened to keep pace with the service needs and aspirations of junior doctors. It is beyond the remit of this paper to determine how this challenge is best addressed, though it is important for the stakeholders and administrators to consider the extent to which difficulties in career progression as a critical care specialist may be hindering the retention of junior doctors in this specialty.

The doctors felt the greatest impact on improving the functioning of the ICUs would arise from better training of doctors, followed by training of nurses and a formal admission/discharge policy for the ICU. The last suggestion probably reflects variations in admission and discharge thresholds of the ICU although ICUs in Sri Lanka are predominantly "closed" in nature with a consultant in charge of the ICU. ${ }^{[10]}$ Continuing the training theme, the doctors felt those who are outside the system (such as foreigners etc.,) could best benefit the ICU by helping with developing protocols and training materials for the unit, followed by incorporating doctors in research and training events such as conferences. This emphasis on training combined with usage of checklists and simple protocols is consistent with previous recommendations for ICUs in resource-limited settings. ${ }^{[6]}$ The perception that the ICUs could most benefit by better training of doctors, including by utilizing external resources in such training, when considered alongside the aspirations of the doctors to specialize in critical care should be seen as a call to widen opportunities in training for these doctors. Further, it should reinforce the need to explore how to better retain trained staff. In contrast, the doctors did not feel that the involvement of outsiders in training ICU nurses in any form would have a good impact. Potential reasons for such a view, including the English language difficulties of the nurses, need further exploration. Possibly, the doctors feel that they would be better placed to facilitate the training of nurses in their ICUs, though the survey did not explore this.

\section{Limitations}

The low response rate of the survey makes generalization difficult. Selection bias due to online nature of the survey has to be considered. The concerns of HCWs in non-HIC to express opinions which they perceive to be critical regarding the system they are part of and the possibility of social desirability bias leading to over-response to questions may have also affected the survey responses. Unfortunately, the survey did not seek to determine what would influence doctors to continue in critical care or leave for other postings.

\section{Conclusion}

Critical care junior doctors in Sri Lankan ICUs, unlike other LMICs, are predominantly from a non-anesthetic background and have a high turnover despite wishing to specialize in critical care. Doctors with an anesthetic background feel more competent in performing ICU skills. ICU junior doctors are more stressed and less happy in comparison to previous non-ICU jobs. In common with recommendations from other settings, they perceive that better training opportunities for junior doctors would be important for their careers and contribute to improving critical care services. Measures to improve training opportunities for these doctors and strategies to improve their retention in ICUs need to be addressed.

\section{Financial support and sponsorship}

Nil.

\section{Conflicts of interest}

There are no conflicts of interest.

\section{RefEREnCes}

1. Kelley MA. Critical care medicine - A new specialty? N Engl J Med 1988;318:1613-7.

2. Dorman T, Angood PB, Angus DC, Clemmer TP, Cohen NH, Durbin CG Jr., et al. Guidelines for critical care medicine training and continuing medical education. Crit Care Med 2004;32:263-72.

3. Fuchs RJ, Berenholtz SM, Dorman T. Do intensivists in ICU improve outcome? Best Pract Res Clin Anaesthesiol 2005;19:125-35.

4. Husain T, Gatward JJ, Hambidge OR, Asogan M, Southwood TJ. Strategies to prevent airway complications: A survey of adult Intensive Care Units in Australia and New Zealand. Br J Anaesth 2012;108:800-6.

5. Astin J, King EC, Bradley T, Bellchambers E, Cook TM. Survey of airway management strategies and experience of non-consultant doctors in Intensive Care Units in the UK. Br J Anaesth 2012;109:821-5.

6. Riviello ED, Letchford S, Achieng L, Newton MW. Critical care in 
resource-poor settings: Lessons learned and future directions. Crit Care Med 2011;39:860-7.

7. Turner EL, Nielsen KR, Jamal SM, von Saint André-von Arnim A, Musa NL. A review of pediatric critical care in resource-limited settings: A Look at past, present, and future directions. Front Pediatr 2016;4:5.

8. Gajic O, Afessa B. Physician staffing models and patient safety in the ICU. Chest 2009;135:1038-44.

9. Bhagwanjee S. Critical care in Africa. Crit Care Clin 2006;22:433-8, viii.

10. Haniffa R, De Silva AP, Iddagoda S, Batawalage H, De Silva ST, Mahipala PG, et al. A cross-sectional survey of critical care services in Sri Lanka: A lower middle-income country. J Crit Care 2014;29:764-8.

11. Friends and family test. Nurs Manage 2012;19:13. [RCN Publishing
Ltd.]. Available from: http://www.dx.doi.org/10.7748/nm.19.8.13.s14. [Last accessed on 2016 Dec 01].

12. Sigera PC, Tunpattu MU, Jayashantha TP, De Silva AP, Athapattu PL, Dondorp A, et al. National profile of physiotherapists in critical care units of Sri Lanka: A low-middle income country. Phys Ther 2016;96:933-9.

13. Kellerman SE, Herold J. Physician response to surveys. A review of the literature. Am J Prev Med 2001;20:61-7.

14. Judson JA, Fisher MM. Intensive care in Australia and New Zealand. Crit Care Clin 2006;22:407-23, vii-viii.

15. Poalillo FE, Jimenez EJ, Falk J. Critical care in the United States of America. Crit Care Clin 2006;22:447-55, ix.

16. Offenstadt G, Moreno R, Palomar M, Gullo A. Intensive care medicine in Europe. Crit Care Clin 2006;22:425-32, viii. 